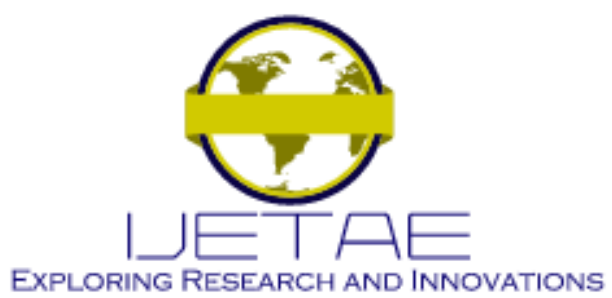

International Journal of Emerging Technology and Advanced Engineering

Website: www.ijetae.com (E-ISSN 2250-2459, Scopus Indexed, ISO 9001:2008 Certified Journal, Volume 11, Issue 11, November 2021)

Manuscript Received: 14 September 2021, Received in Revised form: 22 Oct 2021, Accepted: 03 November 2021

DOI: 10.46338/ijetae1121_01

\title{
Machine Learning Predictor Models in the Electronic Properties of Alkanes based on Degree-Topology Indices
}

\author{
Zubainun Mohamed Zabidi ${ }^{1}$, Ahmad Nazib Alias ${ }^{2}$, Nurul Aimi Zakaria ${ }^{3}$, Zaidatul Salwa Mahmud ${ }^{4}$, Rosliza Ali ${ }^{5}$, \\ Muhamad Kamil Yaakob ${ }^{6}$, Suraya Masrom ${ }^{7}$ \\ ${ }^{1,2,3,4,5}$ Faculty of Applied Sciences, Universiti Teknologi MARA Perak Branch Tapah Campus, Malaysia \\ ${ }^{6}$ Faculty of Applied Sciences, Universiti Teknologi MARA, 40450 Shah Alam, Selangor, Malaysia \\ ${ }^{7}$ Faculty of Computer and Mathematical Sciences, Universiti Teknologi MARA, Perak Branch Tapah Campus, Malaysia
}

\begin{abstract}
New topology indices that are degree-based have been introduced to represent molecular structure from chemical graph theory. The indices give a new sight into the physical properties of the chemical compounds. The correlation of physiochemical properties with chemical graph theory can be done using the Quantitative Structure Properties Relationship (QSPR). Highest Occupied Molecular Orbital (HOMO) and Lowest Unoccupied Molecular Orbital (LUMO) are two basic electronic properties that describe the physiochemical of molecular structure. In computational chemistry, HOMO and LUMO can be calculated by ab initio molecular orbital calculation such as semi-empirical and density functional theory (DFT) method. However, these methods are time-consuming computations. In this paper, predictor model of HOMO and LUMO were developed using Machine Learning algorithms namely Linear Regression, Ridge Regression, LASSO Regression and Elastic Net Regression. The results showed that the performance achievement of each of the machine learning algorithms varied in accordance to the topology indices descriptors and the most outperformed model was presented by Linear Regression with the Moment Balaban Indices (JJ). This paper provides the fundamental design and implementation framework of predicting the HOMO and LUMO electronic properties.
\end{abstract}

Keywords-Elastic Net Regression, electronic properties, LASSO Regression, Machine Learning, QSPR, Ridge Regression, topology indices

\section{INTRODUCTION}

Chemical compounds are vital to the success of every industry. Chemical compound properties serve as the foundation for design and analysis in a variety of domains, including combustion [1], petrochemical [2], and material sciences [3]. The effective use of new and existing chemicals requires knowledge of their properties [4].
The estimation of the physiochemical properties or biological properties of chemical compounds can be done by correlating them with chemical graph theory.

Chemical graph theory is a branch of mathematics which combines graph theory and chemistry. Graph theory is used to mathematically model molecules to gain insight into the physical properties of these chemical compounds [5]. According to this theory, a graph indicates a set of elements of a group and their interrelationships. In chemical graphs, the molecule represented by the graph of suppress-hydrogen with the carbon atom skeleton represents the covalent bond between the carbon-carbon atom. The chemical graph of molecule is represented by a numerical number (topology indices) which is unique for each molecule. Topological indices have been demonstrated to correlate strongly with a variety of biological and physicochemical properties [6]. This shows that they are data-rich and moreover, they can be calculated rapidly and easily [7]. The correlation of physiochemical properties with chemical graph theory can be done using the quantitative structure property relationship (QSPR).

The concept of topological indices was initially expressed in 1947 by Wiener. Wiener index is based on the distance between the vertices [8]. Platt has related the quantitative topology index of Paraffins using the degree based of vertex known as Platt index[9]. The Wiener and Platt index are good topology indices for QSPR of boiling points of hydrocarbons [10]. To date, more than 5000 topological indices can be found in the literature [11]. However, the essential problem in the development occurs when finding the suitable correlation between chemical structures and properties [12]. 


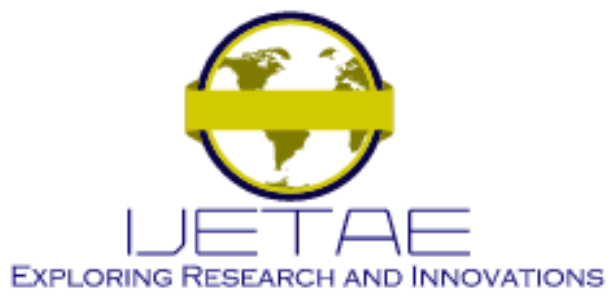

International Journal of Emerging Technology and Advanced Engineering

Website: www.ijetae.com (E-ISSN 2250-2459, Scopus Indexed, ISO 9001:2008 Certified Journal, Volume 11, Issue 11, November 2021)

QSPR modeling produces predictive model derived from the application of statistical tools correlating physicochemical properties (dependent variable) in QSPR models of chemicals with descriptors representative of molecular structure (independent variable) [12, 13]. Moreover, QSPR predicted model based on topological indices have shown stronger theoretical guiding significance, which is very useful for designing new chemical entities with expected properties.

Alkanes are saturated hydrocarbons composed of sigma $(\sigma)$ bonds only. The $\sigma$-bonds responsible for high electronic energy transitions $(\sim 200 \mathrm{~nm})[14]$. The electronic transition is strongly related to the energy difference between the Highest Occupied Molecular Orbital (HOMO) and Lowest Unoccupied Molecular Orbital (LUMO) energy. HOMO and LUMO energy are basic electronic properties that describe the physiochemical of molecular structure. HOMO and LUMO can be calculated using ab initio molecular orbital calculation such as semi-empirical and density functional theory (DFT) method. However, these methods are time-consuming computations [7]. The drawback of this method can be overcome in QSPR models that employ topology indices descriptors. Thus, the aim of this research was to investigate the relationship between HOMO and LUMO of 139 alkanes with several degree-based topological indices. Interestingly, the principle of degreebased topology indices is an analogy with the concept of valence bond in chemistry [15]. Therefore, the correlation of topological indices with HOMO and LUMO using QSPR also indicates the correlation between valence bond with electronic properties. This correlation was investigated using machine learning algorithm to represent a mathematical equation established from Linear Regression, Ridge Regression, LASSO Regression and Elastic Net Regression.

\section{RESEARCH BACKGROUND}

\section{A. Topology Indices}

As mentioned in the introduction, topology indices are one of the molecular descriptors using the application of graph theory. The atoms in the molecular structure are represented by vertexes. While, the chemical bonding is described by the edge[16]. The degree based on the vertex is most commonly used in QSPR $[17,18]$. To describe the method of calculation of topology indices, it is illustrated with specific example, molecules of 2,3-dimethylbutane.
This molecule can be represented by graph $\mathrm{G}(V, E)$ with vertex $(V)$ and edge set $(E)$. Figure 1(a) shows there are 6 vertexes $(V)$ and 5 number of $E$. Therefore, set $V$ can be represented by $\{1,2,3,4,5,6\}$. While set $E$ can be represented by $\{(1,2),(2,3),(2,4),(4,5),(4,6)\}$ Figure 1(b) shows the degree of vertex for 2,3-dimethylbutane. In this paper, we described the vertex degree between edge $i$ and $j$ as $u_{i}$ and $u_{j}$ respectively. For example, Zagreb index is defined as $\mathrm{ZZ1}(\mathrm{G})=\sum_{u_{i} u_{j}}\left(u_{i}+u_{j}\right)$. Therefore, ZZ1 index for 2,3-dimethylbutane $=4(3+1)+(3+3)=25$.

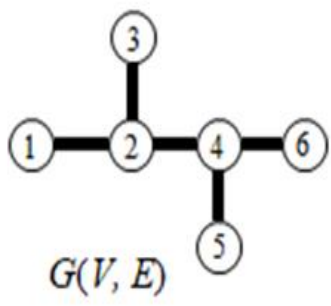

(a)

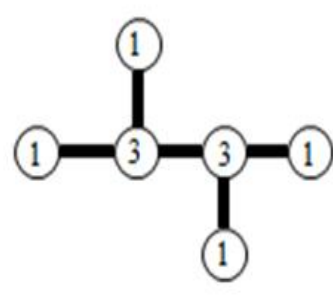

(b)
Figure 1 (a) illustrative molecular graph $\mathrm{G}(V, E)(\mathrm{b})$ vertex-degree for 2,3-dimethylbutane

\section{B. QSPR using Machine Learning}

In $21^{\text {st }}$ century, researchers performed prediction modelling based on single or multiple physicochemical mechanisms[19]. For single mechanism, linear regression analysis, multivariate analysis, and neural network models were primarily used. For multiple mechanisms, knowledgebased systems were often used besides statistical approaches. Nowadays, with the amount of data increasing explosively, it becomes more and more difficult to maintain the completeness of knowledge bases [20].

However, acknowledging the advantages of machine learning that is recently highly recognized by researchers as robust, cost-effective, and high accurate method, there has been progressive research on machine learning for prediction on the desired physical, chemistry and biological properties[21]. Some researchers have used machine learning algorithms, such as random forest [22], artificial neural network (ANN) [23], and other machine learning algorithms [24] to optimize traditional QSAR models in predicting physical, chemical and biological activities. 


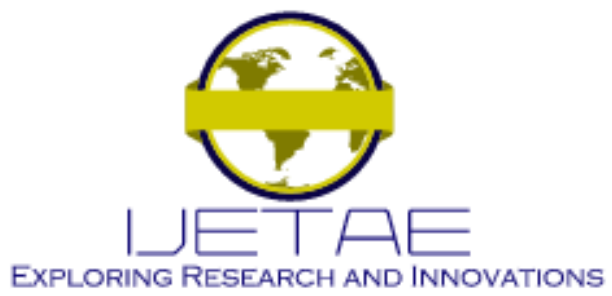

International Journal of Emerging Technology and Advanced Engineering Website: www.ijetae.com (E-ISSN 2250-2459, Scopus Indexed, ISO 9001:2008 Certified Journal, Volume 11, Issue 11, November 2021)

Previous research in [24] revealed that many factors can significantly influence machine learning performances, including the algorithms, datasets, computational representation and model descriptors.
To the best of our knowledge, no single study has addressed the influence of topology indices in machine learning predictor model of electronic properties.

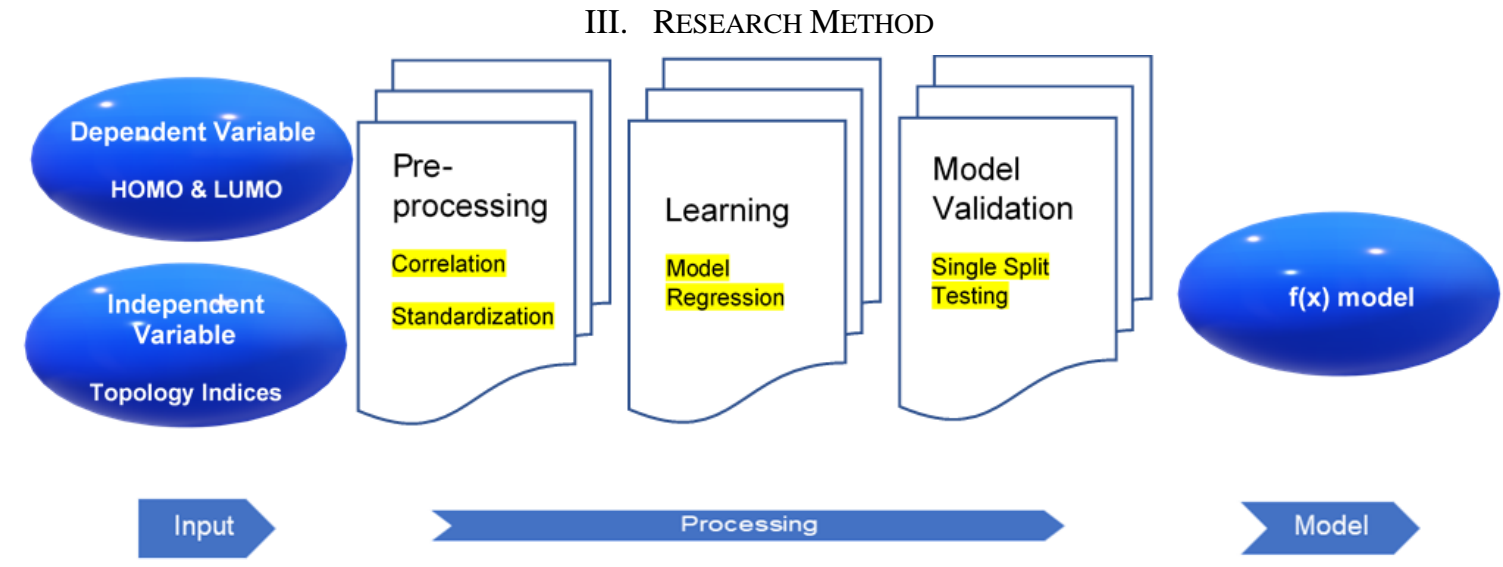

Figure 2: machine learning processing

Mathematical modelling was conducted by regression analysis using machine learning. The process started from data pre-processing and ended with model validation process as illustrated in Figure 2. All the processes were conducted in python 3.9 using scikit-learn library.

\section{A. Topology Indices as the Machine Learning Independent Variable}

Topology indices were used as the input in machine learning. Let $G(V, E)$ represents the molecular graph with the vertex and edge set. The topology indices are defined as below:

Topology I: Zagreb Indices. Zagreb indices are based on the degree of vertex of $G(V, E)$. The degree of vertex analogy with the concept of valence bond in chemistry. Zagreb indices are defined as below [25] :

$$
\begin{aligned}
& \mathrm{ZZ1}(\mathrm{G})=\sum_{u_{i} u_{j}}\left(u_{i}+u_{j}\right) \\
& \mathrm{ZZ2}(\mathrm{G})=\sum_{u_{i} u_{j}}\left(u_{i} u_{j}\right)
\end{aligned}
$$

Topology II: Augmented Zagreb Index. Zagreb index is based on the degree of vertex of $\mathrm{G}(V, E)$. The degree of vertex analogy with the concept of valence bond in chemistry. The augment Zagreb index is defined below [26]:

$$
\operatorname{AM}(\mathrm{G})=\sum_{u_{i} u_{j}}\left(\frac{u_{i} u_{j}}{u_{i}+u_{j}-2}\right)^{3}
$$

Topology III: Sombor Index. Recently, Sombor index was introduced by Gutmann[27]. This Sombor index is based on elementary geometry (using Euclidean metrics) which is given by the equation (3):

$$
\operatorname{SOMBOR}(\mathrm{G})=\sum_{u_{i} u_{j}} \sqrt{\left(u_{i}^{2}+u_{j}^{2}\right)}
$$

Topology IV: Moment Wiener Indices. Wiener indices are calculated from the distance matrix[8]. The improvement of Wiener indices is still ongoing for further application [28]. Moment topology indices were introduced by Dalfo' et al.[29]. Chang at. al. applied these indices to biphenyl and polycyclic hydrocarbons, and extremal polyphenyl chains [28]. For this paper, we define the new value of moment- $\rho$ as follows:

$$
\begin{aligned}
& \operatorname{DD} 1(\mathrm{G})=\frac{1}{2} \sum_{u_{i} u_{j}}\left(u_{i}+u_{j}\right)\left(d_{i j}\right) \\
& \operatorname{DD2}(\mathrm{G})=\frac{1}{2} \sum_{u_{i} u_{j}}\left(u_{i} \cdot u_{j}\right)\left(d_{i j}\right)
\end{aligned}
$$




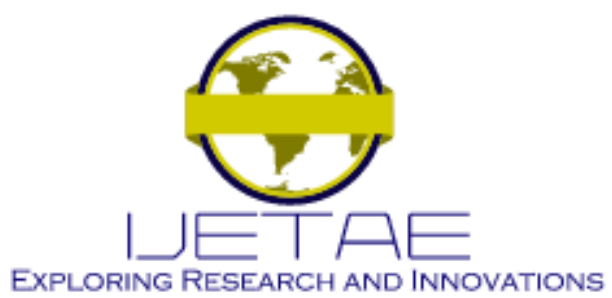

International Journal of Emerging Technology and Advanced Engineering

Website: www.ijetae.com (E-ISSN 2250-2459, Scopus Indexed, ISO 9001:2008 Certified Journal, Volume 11, Issue 11, November 2021)

$$
\begin{aligned}
& \operatorname{DD} 3(\mathrm{G})=\frac{1}{2} \sum_{u_{i} u_{j}}\left|u_{i}-u_{j}\right|\left(d_{i j}\right) \\
& \operatorname{DD} 4(\mathrm{G})=\frac{1}{2} \sum_{u_{i} u_{j}} \sqrt{u_{i}^{2}+u_{j}^{2}}\left(d_{i_{j}}\right)
\end{aligned}
$$

Topology $V$ : Moment Harary Indices. Harary indices of a graph $G(V, E)$ is related with reciprocal distance index [30]. The diagonal element for Harary distance matrix is equal to zero for carbon atom. We also implied the moment Harary indices with the value of moment- $\rho$ as follows:

$$
\begin{aligned}
& \mathrm{HH} 1(\mathrm{G})=\frac{1}{2} \sum_{u_{i} u_{j}}\left(u_{i}+u_{j}\right)\left(d_{i j}^{-1}\right) \\
& \mathrm{HH} 2(\mathrm{G})=\sum_{u_{i} u_{j}}\left(u_{i} \bullet u_{j}\right)\left(d_{i j}^{-1}\right) \\
& \mathrm{HH} 3(\mathrm{G})=\frac{1}{2} \sum_{u_{i} u_{j}}\left|u_{i}-u_{j}\right|\left(d_{i j}^{-1}\right) \\
& \mathrm{HH} 4(\mathrm{G})=\frac{1}{2} \sum_{u_{i} u_{j}} \sqrt{u_{i}^{2}+u_{j}^{2}}\left(d_{i j}^{-1}\right)
\end{aligned}
$$

Topology VI: Moment Balaban Indices. Balaban indices were calculated using the average-distance sum connectivity [31]. Moment Balaban indices are defined as the moment of average-distance sum connectivity that is

$$
\begin{aligned}
& \mathrm{JJ} 1(\mathrm{G})=q \sum_{u_{i} u_{j}} \frac{1}{\sqrt{D 1_{i} D 1_{j}}} \\
& \mathrm{JJ} 2(\mathrm{G})=q \sum_{u_{i} u_{j}} \frac{1}{\sqrt{D 2_{i} D 2_{j}}} \\
& \mathrm{JJ} 3(\mathrm{G})=q \sum_{u_{i} u_{j}} \frac{1}{\sqrt{D 3_{i} D 3_{j}}} \\
& \mathrm{JJ} 4(\mathrm{G})=q \sum_{u_{i} u_{j}} \frac{1}{\sqrt{D 4_{i} D 4_{j}}}
\end{aligned}
$$

where $q$ is the number $q$ of vertex adjacencies. The values of $D 1, D 2, D 3$ and $D 4$ are the moment distance of $\left(u_{i}+u_{j}\right) d_{i j},\left(u_{i} \bullet u_{j}\right) d_{i j},\left|u_{i}-u_{j}\right| d_{i j}$ and $\left(\sqrt{u_{i}^{2}+u_{j}^{2}}\right) d_{i j}$.

\section{B. Highest Occupied Molecular Orbital (HOMO) and Lowest Unoccupied Molecular Orbital (LUMO) as The Machine Learning Dependent}

Semi-empirical quantum chemical method is a computational method to calculate the electronic and molecular orbital properties using self-consistent field molecular orbital theory. In this paper, we employed parametric method 6 (PM6) to calculate HOMO and LUMO. This output was calculated using semi-empirical MOPAC2016, Version: 21.002 James J. P. Stewart software. The input of the structure and geometry optimization was generated using Avogadro version 1.2.0. The geometry optimization used force field method MMFF94s with step per update 4. The detailed calculation can be found in our previous work [32].

\section{Machine Learning Process \\ Correlation of Variables}

In this study, Pearson's correlation coefficient was used to measure the strength of the relationship between independence variables and dependent variable. Figure 3 presents the Python codes to obtain the Pearson' correlation.

As shown in Figure 3, Python codes labeled as In [36] is to calculate the Pearson's correlation coefficient among the independent variables and to the dependent variable (HOMO or LUMO). Out [36] is the output of the program codes from $\operatorname{In}[36]$ that displays the correlation ranked from the strongest to the lowest correlation between independent variables with dependent variable. Python codes in In [37] is to produce the heatmap correlation map of the variables.

\section{Regression Analysis}

In linear regression, the relationship between a dependent variable and independent variables can be written as in equation (1):

$$
Y=\beta X+\varepsilon
$$

where $Y=$ dependent variable, $X=$ independent variable, $\beta=$ regression coefficients and $\varepsilon=$ residuals. 


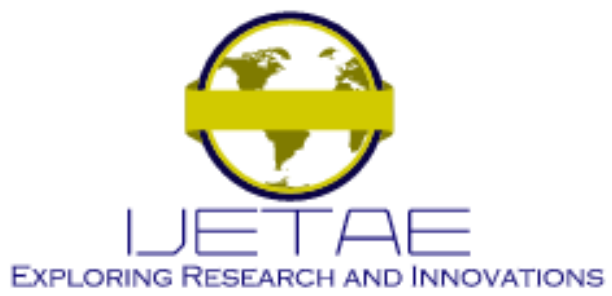

International Journal of Emerging Technology and Advanced Engineering Website: www.ijetae.com (E-ISSN 2250-2459, Scopus Indexed, ISO 9001:2008 Certified Journal, Volume 11, Issue 11, November 2021)

For linear regression, the least square method has been used to find the best fitting linear line. The interest of the least square method in machine learning is to find the best estimation of the parameters using the nearest line to all training datasets. In these studies, we also use three types of regularization system, which are Ridge, least absolute shrinkage, and selection operator (LASSO) and Elastic Net.
In Ridge Regression, a class of biassed estimators, also called Ridge estimators, has been introduced. The bias of LASSO regression has been changed to the sum of absolute values of its components. The combination of Ridge and LASSO biassed estimation regression is called Elastic Net regression.

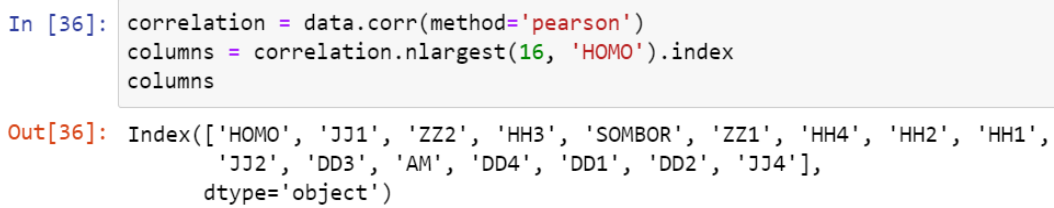

Figure 3: Pearson correlation code in python

Ridge and LASSO biased estimation regression methods are combined in Elastic Net regression. Ridge, LASSO and Elastic Net regression in Lagrangian form [33] is tabulated in Table I.

TABLE I

REGULARIZATION TERMS $\lambda$ FOR RIDGE, LASSO AND ELASTIC NET REGRESSIONS

\begin{tabular}{|c|c|}
\hline Model & Equation \\
\hline Ridge & $\hat{\beta}_{\text {Ridge }}=\underset{\beta}{\operatorname{argmin}}\left\{\|y-X \beta\|_{2}^{2}+\alpha\|\beta\|_{2}^{2}\right\}$ \\
\hline LASSO & $\hat{\beta}_{\text {LASSO }}=\underset{\beta}{\operatorname{argmin}}\left\{\|y-X \beta\|_{2}^{2}+\alpha\|\beta\|_{1}\right\}$ \\
\hline Elastic Net & $\hat{\beta}_{\text {Elastic }}=\underset{\beta}{\operatorname{argmin}}\left\{\|y-X \beta\|_{2}^{2}+\alpha\left[\lambda\|\beta\|_{1}+(1-\lambda)\|\beta\|_{2}^{2}\right]\right\}$ \\
\hline
\end{tabular}

where $\|y-X \beta\|_{2}^{2}$ is the $\mathrm{L}_{2}-$ norm (quadratic) loss

function, $\|\beta\|_{2}^{2}$ is $\mathrm{L}_{2}\|\beta\|_{1}$ is $\mathrm{L}_{1}$ and - norm penalty on $\beta, \alpha$ $>0$ is a parameter of fine turning and $0<\lambda<1$.
Regularized regression analysis requires the standardization, s of all independent variables. In this study, this standardization was calculated using equation (8)

$$
\mathrm{s}=\frac{x_{i}-\bar{x}}{s t d}
$$

with $\bar{x}=$ mean and $s t d=$ standard deviation.

The regulation term $\alpha$ or hyperparameter $\lambda$ varied in the range of 0.001 until 20 . The optimum $\alpha$ was determined by the lowest root mean square error (RMSE) obtained from K-fold Validation.

\section{Model Validation}

Model validation of the study was conducted using single split testing with train and test subsets ratio of $80 \%: 20 \%$. This was to identify the predictive model that provides the best prediction performance and avoid overfitting to training datasets. The model performance was measured by RMSE which indicates the absolute fit of the model and shows how close the predicted values are to the actual data points. It gives an objective representation of the predictive accuracy of the model. RMSE was calculated using equation (9). 


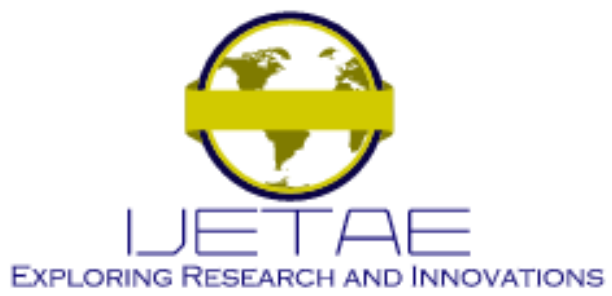

International Journal of Emerging Technology and Advanced Engineering Website: www.ijetae.com (E-ISSN 2250-2459, Scopus Indexed, ISO 9001:2008 Certified Journal, Volume 11, Issue 11, November 2021)

$$
\operatorname{RMSE}=\sqrt{\frac{1}{N} \sum_{i=l}^{N}\left(y_{i}-y\right)^{2}}
$$

The coefficient of determination $\mathrm{R}^{2}$ which is dimensionless goodness-of-fit indicator, represents the proportion of variance of $y$ that is explained by independent variables in the model. It provides an indication of goodness of fit and therefore a measure of how well unseen samples are likely to be predicted by the model, through the proportion of explained variance. $\mathrm{R}^{2}$ was calculated using equation (10).

$$
\mathrm{R}^{2}=1-\frac{\sum\left(y_{i}-y\right)^{2}}{\sum\left(y_{i}-\bar{y}\right)^{2}}
$$

\section{REsults AND Discussions}

A. Correlations between topology indices to HOMO and LUMO

Figure 4 and Figure 5 present the Pearson correlation of each topology index with HOMO and LUMO respectively.

In Figure 4, the topology indices can be grouped as strong, moderate and low correlations with HOMO. The strong correlation is presented by JJ1, ZZ2, HH3, SOMBOR, ZZ1, HH4, HH2, HH1 and JJ2 with correlation values between 0.63 to 0.85 . The correlation values of 0.36 to 0.5 are moderate correlation, which are presented by DD3 and AM. The blue color in Figure 4 shows a low correlation (0.11-0.23) described by DD4, DD1, DD2 and JJ4.

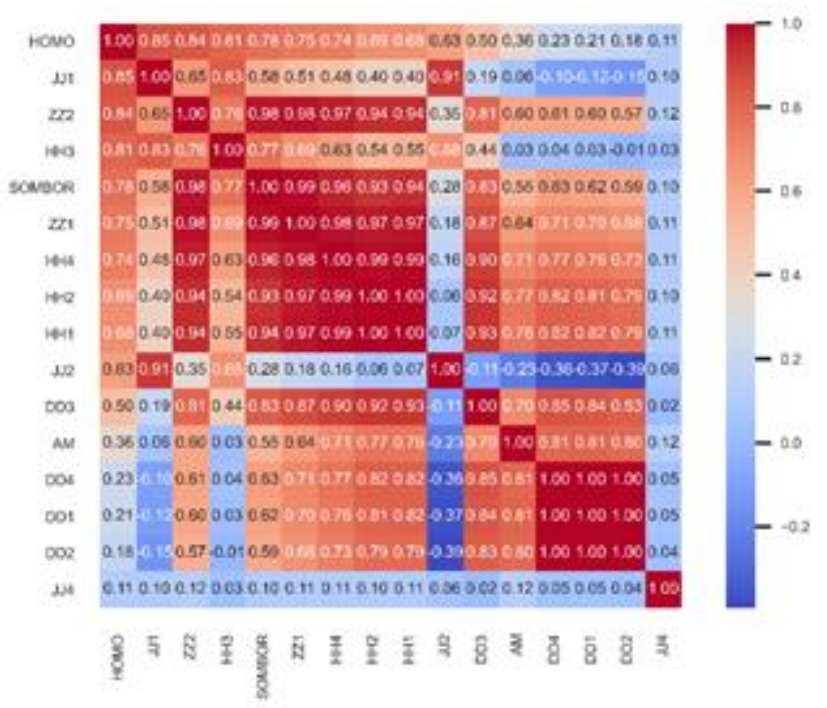

Figure 4: Heatmap plot of topology indices with HOMO

Additionally, the correlation matrix plot shows the existence of multicollinearity. SOMBOR topology index indicate a strong correlation with $\mathrm{ZZ1}, \mathrm{ZZ2}, \mathrm{HH} 4, \mathrm{HH} 2$, HH1 while DD3 DD4 also indicate a strong correlation with DD1 and DD2.

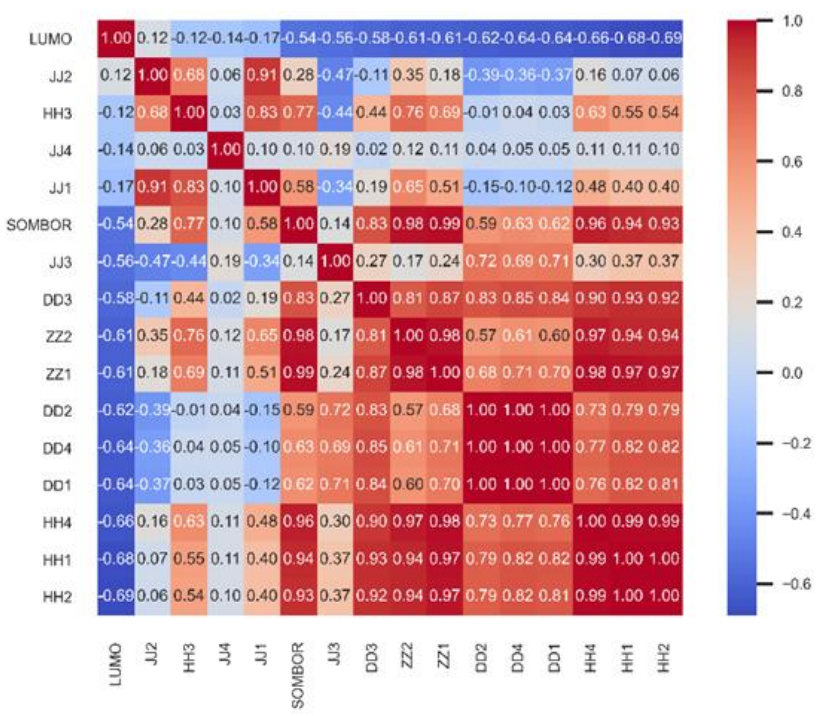

Figure 5: Heatmap plot of topology indices with LUMO 


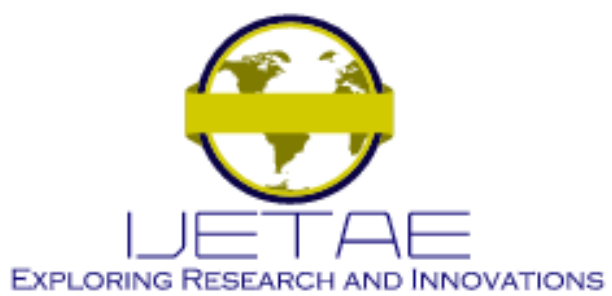

International Journal of Emerging Technology and Advanced Engineering Website: www.ijetae.com (E-ISSN 2250-2459, Scopus Indexed, ISO 9001:2008 Certified Journal, Volume 11, Issue 11, November 2021)

Besides, JJ1 indicates a low correlation with DD3, AM, DD4, DD1, DD2 and JJ4, while JJ4 also indicates a low correlation with all the independent variables. The strong correlation between DD1, DD2, DD3 and DD4 indicates the existence of multicollinearity among them. Hence, other regularization regression such as Ridge, LASSO and Elastic Net needs to perform to improve the performance of Linear Regression.

Meanwhile, Figure 5 indicates the correlation among independent variables with LUMO. Moderate and low correlations can be seen between independent variables and LUMO as in Figure 5. Moderate correlations (0.54-0.69) are from SOMBOR, JJ3, DD3, ZZ2, ZZ1, DD2, DD4, DD1, HH4, HH1, HH2 while low correlations (0.12-0.17) are from JJ2, HH3, JJ4, JJ1. Moreover, SOMBOR, JJ3, DD3, ZZ2, ZZ1, DD42, DD4, DD1, HH4, HH1 and HH2 have strong correlation with each other.

\section{B. Accuracy Results}

Table II presents the accuracy results for all machine learning algorithms for HOMO. Regardless of the topology indices, the most outperformed machine learning algorithm is presented by Linear Regression. The highest coefficient of determination $\mathrm{R}^{2}$ and the lowest root-meansquare-error RMSE of training set for HOMO is with JJ topology indices in Linear Regression. The values of $\mathrm{R}^{2}=$ 0.875105 and $\mathrm{RMSE}=0.06672$ indicate that the model was acceptable with goodness-of-fit. On the test set, the model with JJ had shown its ability to achieve good accurate of predictive results with $\mathrm{R}^{2}=0.854459$ and $\mathrm{RMSE}=0.06672$. By comparing the topology indices, the performance achievement of Linear Regression can be ranked as JJ, ZZ, HH, DD, SOMBOR and AM.

The need of regulation technique to get stable and reliable estimations was also studied. Multicollinearity might exist for DD topology indices because the strong correlation between DD1, DD2, DD3 and DD4 is 1.0 (Figure 4) which indicates a strong linear correlation between independent variables.
Moreover, $\mathrm{R}^{2}$ and RMSE showed high deviation between Linear, Ridge, LASSO and Elastic Net Regression.

Figure 6 presents the plot of RMSE versus $\alpha$ for Ridge, LASSO and Elastic Net Regression for HOMO. When comparing with all types of topology indices, Ridge Regression model scored the lowest RMSE. This means Ridge Regression outperformed the regulation regression model. The lowest RMSE for each regression model is an optimum $\alpha$ and their mathematical model was evaluated.

Regularization regression is a form of regression in which the coefficient estimates are constrained to zero. Regulation will reduce the model variance while having little effect on its bias. This can be done by tuning parameter alpha, $\alpha$ in the regulation systems. As the value of $\alpha$ increases, the rate of coefficients decreases, thus lowering the variance. So, $\alpha$ must becarefully selected at optimum level. Failure to determine the optimum level will cause the predicted model to lose significant properties, resulting in bias and underfitting.

Linear Regression model needs to be reconsidered when data variable grows and will cause an overfitting between the multiple variables. The strong correlation between the independent variables is one of the factors that cause an overfitting of the mathematical model. The overfitting is a condition when the mathematical model has a high variance and low bias. The overfitting will cause the model prediction tolerable to predict the dependent variable at the training data and difficult to generalize well with other data set.

In Ridge regulation, the correction shrinkage the coefficient of each of independent variable in order to reduce the variance of the mathematical model. This can be compared between the value of coefficients of the independent variables between Ridge Regression with Linear Regression for each of the topology indices. $\alpha$ controls the power of the penalty by selecting the relative importance of data-dependent practical error and penalty. 


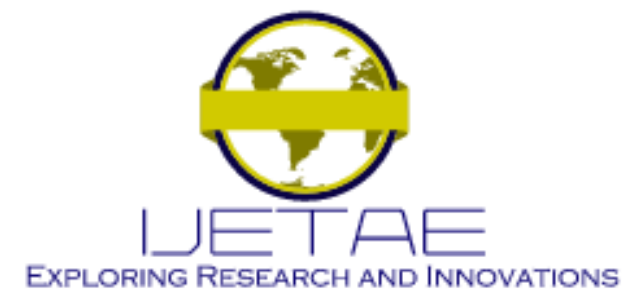

International Journal of Emerging Technology and Advanced Engineering

Website: www.ijetae.com (E-ISSN 2250-2459, Scopus Indexed, ISO 9001:2008 Certified Journal, Volume 11, Issue 11, November 2021)

TABLE II

ACCURACY RESULTS FOR ALL MACHINE LEARNING ALGORITHMS FOR HOMO

\begin{tabular}{|c|c|c|c|c|c|c|c|c|}
\hline \multirow{2}{*}{$\begin{array}{l}\text { Topology } \\
\text { Indices }\end{array}$} & \multirow{2}{*}{ Regression } & \multirow{2}{*}{ Mathematical Model } & \multirow{2}{*}{$\begin{array}{l}\text { Optimum } \\
\text { Alpha }\end{array}$} & \multirow{2}{*}{$\begin{array}{l}\text { Lowest } \\
\text { RMSE }\end{array}$} & \multicolumn{2}{|c|}{ Train } & \multicolumn{2}{|c|}{ Test } \\
\hline & & & & & $\mathrm{R}^{2}$ & RMSE & $\mathrm{R}^{2}$ & RMSE \\
\hline \multirow{4}{*}{$\mathrm{ZZ}$} & $\begin{array}{l}\text { Linear } \\
\text { Regression }\end{array}$ & $-0.3540 Z Z 1+0.5020 Z Z 2-10.6663$ & & & 0.826333 & 0.078676 & 0.909064 & 0.056737 \\
\hline & Ridge & $0.4499 Z Z 1-0.2997 Z Z 2-10.6623$ & 0.01 & 0.07219 & 0.848251 & 0.071258 & 0.836623 & 0.084994 \\
\hline & Lasso & $0.1466 Z Z 1-10.6623$ & 0.01 & 0.09484 & 0.730038 & 0.095043 & 0.642136 & 0.125792 \\
\hline & Elastic Net & $0.0111 Z Z 1-11.0634$ & 0.01 & 0.09013 & 0.761286 & 0.089374 & 0.682011 & 0.118577 \\
\hline \multirow{4}{*}{$\mathrm{AM}$} & $\begin{array}{l}\text { Linear } \\
\text { Regression }\end{array}$ & $0.0590 \mathrm{AM}-10.6663$ & & & 0.097758 & 0.179327 & 0.191816 & 0.169143 \\
\hline & Ridge & 0.0040 AM-10.8859 & 0.01 & 0.1713 & 0.132258 & 0.170399 & 0.113677 & 0.197966 \\
\hline & Lasso & $0.0003 \mathrm{AM}-10.6814$ & 0.01 & 0.1713 & 0.021557 & 0.180942 & 0.019509 & 0.208217 \\
\hline & Elastic Net & $0.0022 \mathrm{AM}-10.7834$ & 0.01 & 0.1713 & 0.104461 & 0.173106 & 0.092914 & 0.200271 \\
\hline \multirow{3}{*}{ SOMBOR } & $\begin{array}{l}\text { Linear } \\
\text { Regression }\end{array}$ & 0.1438 SOMBOR-10.6663 & & & 0.580328 & 0.122304 & 0.683218 & 0.105896 \\
\hline & Ridge & 0.0238 SOMBOR-11.2991 & 1 & 0.11116 & 0.631745 & 0.111006 & 0.530854 & 0.144028 \\
\hline & Elastic Net & 0.0103 SOMBOR-10.9374 & 1 & 0.14013 & 0.427823 & 0.138368 & 0.330597 & 0.172043 \\
\hline \multirow{4}{*}{ DD } & $\begin{array}{l}\text { Linear } \\
\text { Regression }\end{array}$ & $\begin{array}{l}-0.2913 \mathrm{DD} 1-4.0970 \mathrm{DD} 2- \\
0.1392 \mathrm{DD} 3+4.5343 \mathrm{DD} 4-10.6662\end{array}$ & & & 0.73394 & 0.097381 & 0.543112 & 0.127176 \\
\hline & Ridge & $\begin{array}{l}-0.0424 \mathrm{DD} 1-2.4248 \mathrm{DD} 2+0.3293 \mathrm{DD} 3- \\
2.6787 \mathrm{DD} 4-10.6623\end{array}$ & 0.01 & 0.10062 & 0.723206 & 0.096239 & 0.610742 & 0.131194 \\
\hline & Lasso & $0.1508 D D 1-0.0779 D D 4-10.6623$ & 0.01 & 0.1433 & 0.445041 & 0.138984 & 0.340697 & 0.168234 \\
\hline & Elastic Net & 0.1746 DD1-0.1018DD4-10.6623 & 0.01 & 0.14155 & 0.438568 & 0.13627 & 0.359912 & 0.168185 \\
\hline \multirow{4}{*}{$\mathrm{HH}$} & $\begin{array}{l}\text { Linear } \\
\text { Regression }\end{array}$ & $\begin{array}{l}-0.8172 \mathrm{HH} 1+0.6094 \mathrm{HH} 2+0.0958 \mathrm{HH} 3 \\
+0.2860 \mathrm{HH} 4-10.6662\end{array}$ & & & 0.776729 & 0.089207 & 0.792908 & 0.085621 \\
\hline & Ridge & $\begin{array}{l}0.0937 \mathrm{HH} 1+0.2301 \mathrm{HH} 2+0.4447 \mathrm{HH} 3- \\
0.5977 \mathrm{HH} 4-10.6623\end{array}$ & 0.01 & 0.08764 & 0.784539 & 0.084909 & 0.764397 & 0.102067 \\
\hline & Lasso & $0.0963 \mathrm{HH} 1+0.0650 \mathrm{HH} 2-10.6623$ & 0.01 & 0.09359 & 0.748114 & 0.091806 & 0.692622 & 0.116582 \\
\hline & Elastic Net & $\begin{array}{l}0.1019 \mathrm{HH} 1+.04362 \mathrm{HH} 2+0.0226 \mathrm{HH} 3- \\
10.66234\end{array}$ & 0.01 & 0.09306 & 0.751233 & 0.091236 & 0.702067 & 0.114777 \\
\hline \multirow{4}{*}{ JJ } & $\begin{array}{l}\text { Linear } \\
\text { Regression }\end{array}$ & $\begin{array}{l}0.3181 \mathrm{JJ} 1-0.1718 \mathrm{JJ} 2+0.0044 \mathrm{JJ} 3-0.0035 \mathrm{JJ} 4- \\
10.6662\end{array}$ & & & 0.875105 & 0.06672 & 0.854459 & 0.071778 \\
\hline & Ridge & $\begin{array}{l}0.2724 J J-0.1247 \mathrm{JJ} 2-0.0043 \mathrm{JJ} 3+0.0130 \mathrm{JJ} 4- \\
10.6623\end{array}$ & 1 & 0.08585 & 0.857946 & 0.068944 & 0.878941 & 0.073163 \\
\hline & Lasso & $0.1789 \mathrm{JJ} 1-0.0302 \mathrm{JJ} 2+0.0140 \mathrm{JJ} 4-10.6623$ & 0.01 & 0.08593 & 0.791911 & 0.083444 & 0.775294 & 0.099678 \\
\hline & Elastic Net & $0.2269 \mathrm{JJ} 1-0.0792 \mathrm{JJ} 2+0.0125 \mathrm{JJ} 4-10.6623$ & 0.01 & 0.07587 & 0.837027 & 0.073846 & 0.837807 & 0.084686 \\
\hline
\end{tabular}




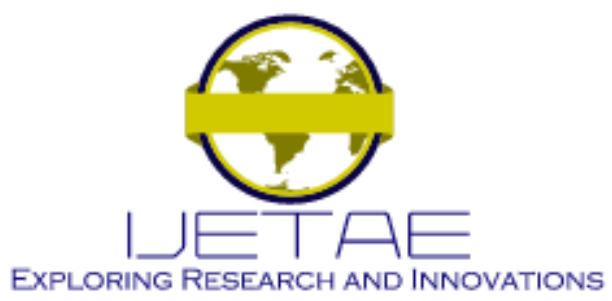

International Journal of Emerging Technology and Advanced Engineering Website: www.ijetae.com (E-ISSN 2250-2459, Scopus Indexed, ISO 9001:2008 Certified Journal, Volume 11, Issue 11, November 2021)

The higher the value of penalty, the greater is the amount of shrinkage. The penalizing of the absolute values of the coefficients introduces shrinkage towards zero in LASSO regulation. The penalties act as a continuous variable selection tool. For HOMO, as for $\mathrm{HH}$ topology indices the $\mathrm{HH} 3$ and $\mathrm{HH} 4$ were eliminated, $\mathrm{ZZ2}$ was eliminated for $\mathrm{ZZ}$ topology indices, JJ3 was eliminated for $\mathrm{JJ}$ topology indices and DD2 and DD3 were eliminated for DD topology indices.
The effect of penalizing in Elastic Net regulation combined of the Ridge and LASSO regulation. The coefficient of each of independent variable had shrinkage and some of the independent variables were eliminated. For $\mathrm{HOMO}$, as for $\mathrm{HH}$ topology indices, HH4 was eliminated, ZZ2 was eliminated for ZZ topology indices, JJ3 was eliminated for JJ topology indices and DD2 and DD3 were eliminated for DD topology indices. Ridge regulation improved the mathematical model for $\mathrm{HH}$, SOMBOR, AM, $\mathrm{ZZ}$ and DD.
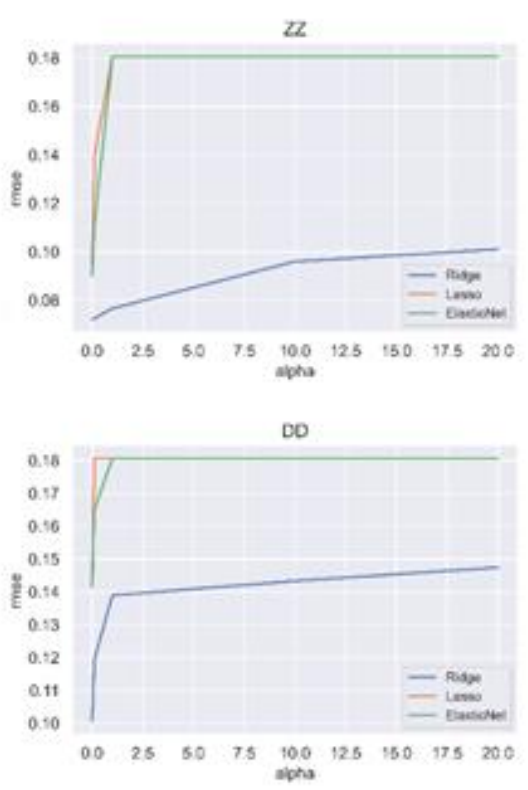
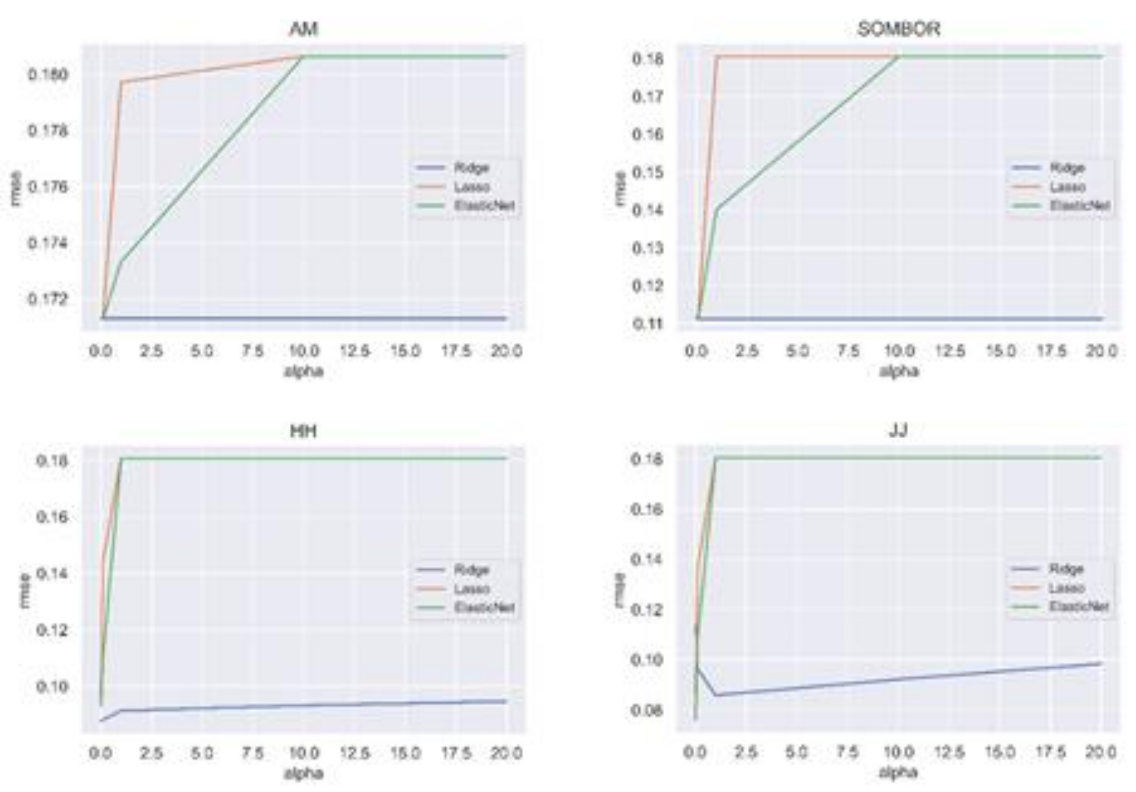

Figure 6 RMSE versus alpha for all topology indices predictor model for HOMO 


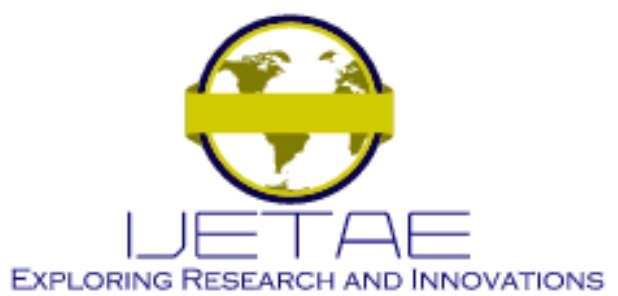

International Journal of Emerging Technology and Advanced Engineering

Website: www.ijetae.com (E-ISSN 2250-2459, Scopus Indexed, ISO 9001:2008 Certified Journal, Volume 11, Issue 11, November 2021)

TABLE III

ACCURACY RESULTS FOR ALL MACHINE LEARNING ALGORITHMS FOR LUMO

\begin{tabular}{|c|c|c|c|c|c|c|c|c|}
\hline \multirow{2}{*}{$\begin{array}{l}\text { Topology } \\
\text { Indices }\end{array}$} & \multirow{2}{*}{ Regression } & \multirow{2}{*}{ Mathematical Model } & \multirow{2}{*}{$\begin{array}{l}\text { Optimum } \\
\text { Alpha }\end{array}$} & \multirow{2}{*}{$\begin{array}{l}\text { Lowest } \\
\text { RMSE }\end{array}$} & \multicolumn{2}{|c|}{ Train } & \multicolumn{2}{|c|}{ Test } \\
\hline & & & & & $\mathrm{R}^{2}$ & RMSE & $\mathrm{R}^{2}$ & RMSE \\
\hline \multirow{4}{*}{$\mathrm{ZZ}$} & $\begin{array}{l}\text { Linear } \\
\text { Regression }\end{array}$ & $-0.0534 Z Z 1+0.0060 Z Z 2+4.0644$ & & & 0.383034 & 0.060322 & 0.209964 & 0.050914 \\
\hline & Ridge & $-0.0206 Z Z 1-0.0197 Z Z 2+4.0719$ & 10 & 0.05214 & 0.38426 & 0.0531 & 0.326006 & 0.07382 \\
\hline & Lasso & $-0.0184 Z Z 1-0.0137 Z Z 2+4.0719$ & 0.01 & 0.0529 & 0.362953 & 0.054011 & 0.28497 & 0.076034 \\
\hline & Elastic Net & $-0.0204 Z Z 1-0.0166 Z Z 2+4.0719$ & 0.01 & 0.0524 & 0.379299 & 0.053314 & 0.311232 & 0.074625 \\
\hline \multirow{4}{*}{ AM } & $\begin{array}{l}\text { Linear } \\
\text { Regression }\end{array}$ & $-0.0565 \mathrm{AM}+4.0644$ & & & 0.541796 & 0.051984 & 0.572691 & 0.037444 \\
\hline & Ridge & $-0.0030 \mathrm{AM}+4.2368$ & 0.001 & 0.04483 & 0.526126 & 0.046583 & 0.595825 & 0.057165 \\
\hline & Lasso & $-0.0030 \mathrm{AM}+4.2366$ & 0.001 & 0.04484 & 0.526126 & 0.046583 & 0.595527 & 0.057186 \\
\hline & Elastic Net & $-0.0030 \mathrm{AM}+4.2367$ & 0.001 & 0.04484 & 0.526126 & 0.046583 & 0.595676 & 0.057176 \\
\hline \multirow{4}{*}{ SOMBOR } & $\begin{array}{l}\text { Linear } \\
\text { Regression }\end{array}$ & $-0.0418 \mathrm{SOMBOR}+4.0644$ & & & 0.295818 & 0.064444 & 0.187214 & 0.051642 \\
\hline & Ridge & $-0.0050 \mathrm{SOMBOR}+4.2041$ & 0.01 & 0.05538 & 0.294839 & 0.056826 & 0.220469 & 0.079389 \\
\hline & LASSO & $-0.0059 \mathrm{SOMBOR}+4.2288$ & 0.01 & 0.05543 & 0.305803 & 0.056382 & 0.243735 & 0.078196 \\
\hline & Elastic Net & $-0.0060 \mathrm{SOMBOR}+4.2324$ & 0.01 & 0.05546 & 0.30624 & 0.056364 & 0.24653 & 0.078051 \\
\hline \multirow{4}{*}{ DD } & $\begin{array}{l}\text { Linear } \\
\text { Regression }\end{array}$ & $\begin{array}{l}-0.2913 \mathrm{DD} 1-4.0970 \mathrm{DD} 2- \\
0.1392 \mathrm{DD} 3+4.5343 \mathrm{DD} 4-10.6663\end{array}$ & & & 0.555677 & 0.051191 & 0.644735 & 0.034142 \\
\hline & Ridge & $\begin{array}{l}-0.0424 D D 1-2.4249 D D 2+0.3293 D D 3- \\
2.67866007 D D 4-10.6623\end{array}$ & 0.01 & 0.04326 & 0.567347 & 0.044511 & 0.507994 & 0.063071 \\
\hline & Lasso & 0.1508DD1-0.0779DD4-10.6623 & 0.01 & 0.05021 & 0.408647 & 0.052038 & 0.343166 & 0.072874 \\
\hline & Elastic Net & 0.1746DD1-0.1018DD4-10.6623 & 0.01 & 0.05021 & 0.425946 & 0.051272 & 0.354116 & 0.072264 \\
\hline \multirow{4}{*}{$\mathrm{HH}$} & $\begin{array}{l}\text { Linear } \\
\text { Regression }\end{array}$ & $\begin{array}{l}0.1418 \mathrm{HH} 1-0.1436 \mathrm{HH} 2+0.0318 \mathrm{HH} 3- \\
0.0667 \mathrm{HH} 4+4.0644\end{array}$ & & & 0.562763 & 0.050781 & 0.571107 & 0.037513 \\
\hline & Ridge & $\begin{array}{l}0.0310 \mathrm{HH} 1-0.0415 \mathrm{HH} 2-0.0064 \mathrm{HH} 3- \\
0.0174 \mathrm{HH} 4+4.0719\end{array}$ & 1 & 0.04258 & 0.586084 & 0.043537 & 0.519458 & 0.062332 \\
\hline & Lasso & $0.0017 \mathrm{HH} 1-0.0380 \mathrm{HH} 4+4.0719$ & 0.01 & 0.04756 & 0.473652 & 0.049095 & 0.413463 & 0.068864 \\
\hline & Elastic Net & $0.0017 \mathrm{HH} 1-0.0026 \mathrm{HH} 4+4.2078$ & 0.01 & 0.04409 & 0.549894 & 0.0454 & 0.489527 & 0.064244 \\
\hline \multirow{4}{*}{$\mathrm{JJ}$} & $\begin{array}{l}\text { Linear } \\
\text { Regression }\end{array}$ & $\begin{array}{l}-0.1128 \mathrm{JJ} 1+0.1002 \mathrm{JJ} 2- \\
0.03402 \mathrm{JJ} 3+0.0024 \mathrm{JJ} 4+4.0644\end{array}$ & & & 0.685392 & 0.043075 & 0.41857 & 0.043678 \\
\hline & Ridge & $\begin{array}{l}0.0314 \mathrm{JJ} 1+0.0015 \mathrm{JJ} 2-0.0486 \mathrm{JJ} 3- \\
0.0361 \mathrm{JJ} 4+4.0719 \\
\end{array}$ & 10 & 0.04761 & 0.557888 & 0.044995 & 0.564659 & 0.059328 \\
\hline & Lasso & $-0.0127 \mathrm{JJ} 3-0.0314 \mathrm{JJ} 4+4.0719$ & 0.01 & 0.05069 & 0.387468 & 0.052962 & 0.376531 & 0.070999 \\
\hline & Elastic Net & $0.0136 \mathrm{JJ} 1-0.0315 \mathrm{JJ} 3-0.0362 \mathrm{JJ} 4+4.0719$ & 0.01 & 0.04798 & 0.491487 & 0.048256 & 0.487089 & 0.064397 \\
\hline
\end{tabular}




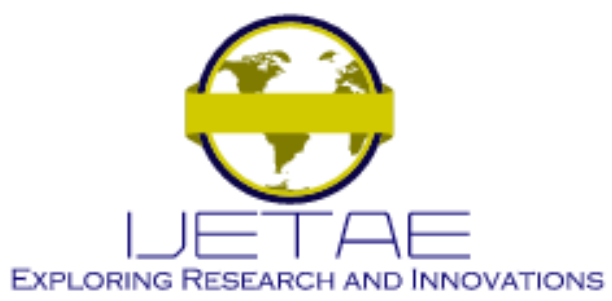

International Journal of Emerging Technology and Advanced Engineering

Website: www.ijetae.com (E-ISSN 2250-2459, Scopus Indexed, ISO 9001:2008 Certified Journal, Volume 11, Issue 11, November 2021)

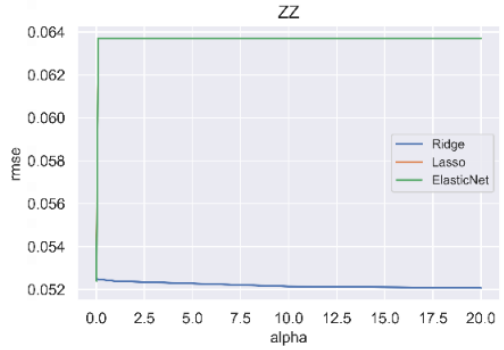

DD

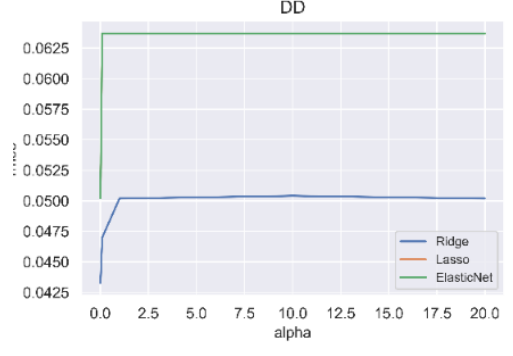

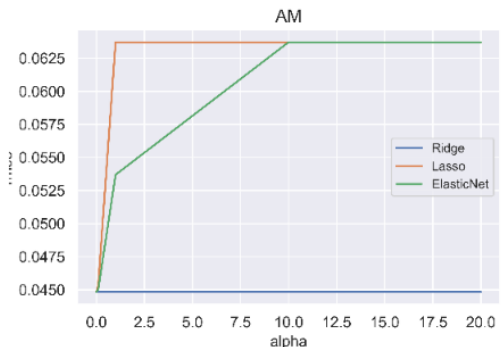

$\mathrm{HH}$

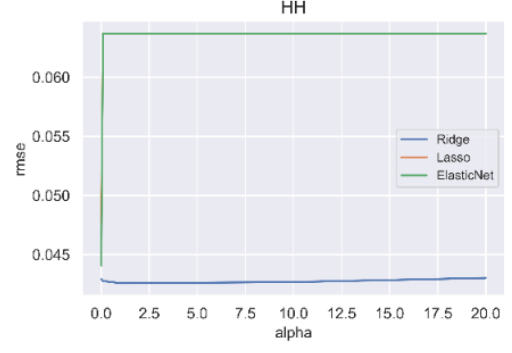

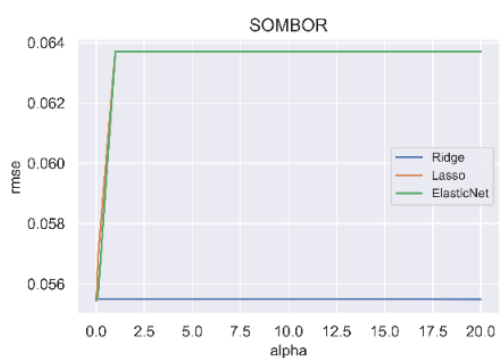

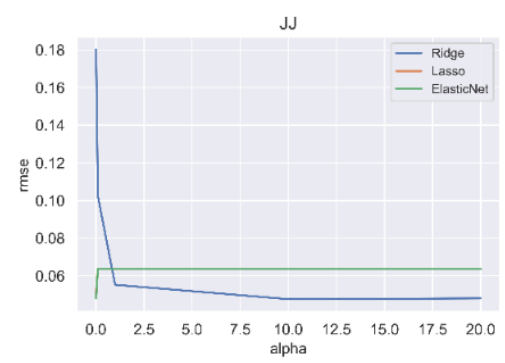

Figure 7 RMSE versus alpha for all topology indices predictor model for LUMO

Table III presents the accuracy results for all machine learning algorithms for LUMO. The highest coefficient of determination $\mathrm{R}^{2}$ and the lowest root-mean-square-error RMSE of training set is $\mathrm{HH}$ for Linear Regression model. This indicates the regression model by $\mathrm{HH}$ outperformed machine learning algorithm. $\mathrm{R}^{2}=0.562763$ and $\mathrm{RMSE}=$ 0.043537 for Linear Regression indicates that the developed model was acceptable with goodness-of-fit. On the test set, $\mathrm{R}^{2}=0.571107$ and $\mathrm{RMSE}=0.037513$, which suggests that the developed model also presented high predictive ability compared to other topology indices mathematical models. All the results of $\mathrm{R}^{2}$ of these topology indices $>0.5$ for train and test set indicate that the developed model was acceptable with goodness-of-fit. Despite that, SOMBOR and ZZ topology indices are not suitable for mathematical model for LUMO since the value of $\mathrm{R}^{2}<0.5$. By comparing the topology indices, the performance achievement of Linear Regression can be ranked as JJ, HH, DD, AM, ZZ and SOMBOR. However, $\mathrm{R}^{2}$ for $\mathrm{JJ}$ indices are not stable, and the regulation regression model also indicates a low value of $R^{2}$. Multicollinearity might exist for $\mathrm{JJ}$ topology indices because $\mathrm{R}^{2}$ and RMSE showed high deviation between Linear, Ridge, LASSO and Elastic Net Regression.
Meanwhile, Figure 7 indicates RMSE versus alpha for all topology indices mathematical models for LUMO. Similar to HOMO, when comparing with all type topology indices, Ridge Regression model also scored the lowest RMSE. This indicates that Ridge Regression outperformed the regulation regression model. The lowest RMSE for each regression model is an optimum $\alpha$ and their predicting model was also evaluated. For LUMO, the effect of penalizing by square values, also makes the correction to shrinkage the coefficient of each of independent variable in order to reduce the variance of the predicted model.

The effect of LASSO regulation in LUMO, as for $\mathrm{HH}$ topology indices, the $\mathrm{HH} 2$ and $\mathrm{HH} 3$ were eliminated, JJ1 and $\mathrm{JJ} 2$ were eliminated for $\mathrm{JJ}$ topology indices, and DD2 and DD3 were eliminated for DD topology indices. This indicates the penalties also act as a continuous variable selection tool.

For the effect of penalizing in elastic net regulation for LUMO, as for $\mathrm{HH}$ topology indices, $\mathrm{HH} 2$ and $\mathrm{HH} 3$ were eliminated, JJ2 was eliminated for $\mathrm{JJ}$ topology indices, and DD2 and DD3 were eliminated for DD topology indices. Similar to HOMO, Ridge regulation improved the mathematical model for $\mathrm{HH}, \mathrm{ZZ}$ and $\mathrm{DD}$ since their $\mathrm{R}^{2}$ increased and RMSE decreased when compared to linear regression mathematical model. 


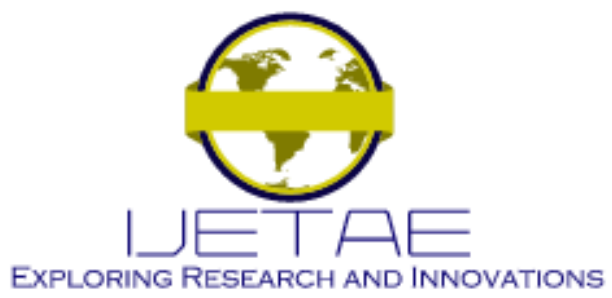

International Journal of Emerging Technology and Advanced Engineering

Website: www.ijetae.com (E-ISSN 2250-2459, Scopus Indexed, ISO 9001:2008 Certified Journal, Volume 11, Issue 11, November 2021)

Li et al.[34] has reported the energy gaps of porphyrins using machine learning have high accuracy with RMSE < $0.06 \mathrm{eV}$ using an Artificial Neural Network. While Pereira et al. [35] have explored the HOMO LUMO energy of neutral organic molecules using random forest, support vector machines, multilayer perceptron, and model regression tree models. They found that HOMO and LUMO energy accuracies were up to 0.15 and $0.16 \mathrm{eV}$.

The correlation between the observed HOMO and predicted values for JJ topology (Linear Regression) and the correlation between the observed LUMO and predicted values for HH (Ridge Regression) are plotted in Figure 8 (a) dan Figure 8 (b) respectively. HOMO and LUMO are among the electronic properties of alkanes that explain the behavior of electron in molecular structure. The electrons in this molecule are responsible for $\mathrm{C}-\mathrm{H}$ bond and basic framework $\mathrm{C}-\mathrm{C}$ bonds.

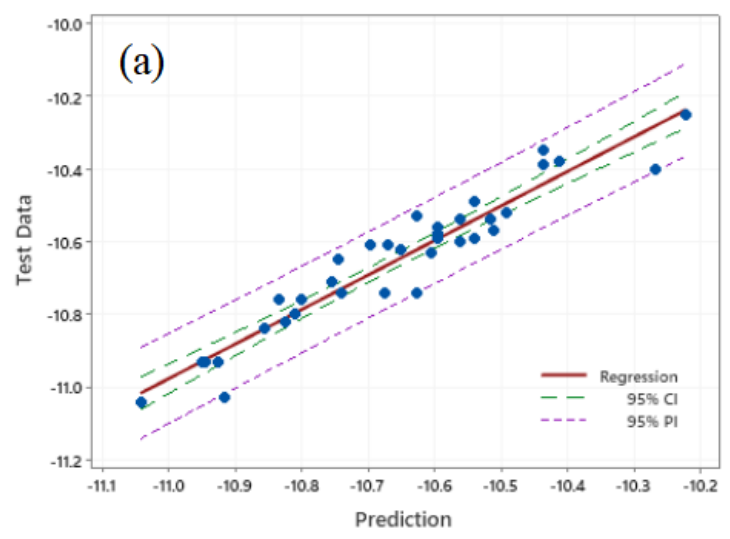

Since in topology approach suppress-hydrogen, therefore, the relation of HOMO and LUMO with topology indices involves the localized $\sigma$ electron. The electronic properties of molecular structure require the localization of electrons and also electron spreading throughout the whole molecule. The machine learning algorithm is able to correlate between the localized of electron through the whole molecule using degree-based topology indices as mentioned in the introduction. Machine learning algorithm approach for HOMO and LUMO provides a suitable modeling for molecular orbital description of molecule in term of the equivalent molecular structure with molecular orbital approximately localized by $\sigma$ electron. These relationships are closely associated with the interpretation of electron pair as the chemical bond which cogitates the mathematical modeling.

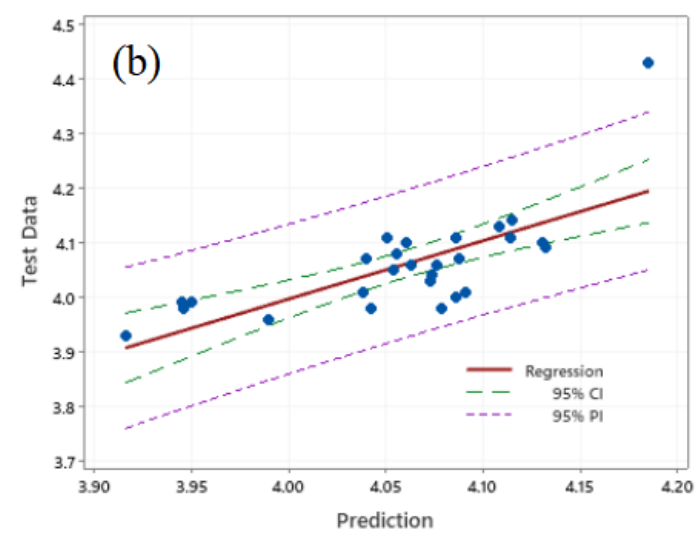

Figure 8 (a) Correlation between the observed HOMO and predicted values for JJ topology (Linear Regression); (b) correlation between the observed LUMO and predicted values for HH topology (Ridge Regression)

\section{CONCLUSIONS}

Degree-Topology Indices enabled the estimation of HOMO and LUMO with RMSE between 0.04 to 0.2. For HOMO, by comparing the topology indices, the performance achievement of linear regression can be ranked as JJ, ZZ, HH, DD, SOMBOR and AM.
Multicollinearity might exist for DD topology indices because of strong correlation between DD1, DD2, DD3 and DD4 which indicates strong linear correlation between the independent variables and $\mathrm{R}^{2}$ and RMSE showed high deviation between Linear, Ridge, LASSO and Elastic Net Regression. Ridge regulation was shown to improve the mathematical model for $\mathrm{HH}, \mathrm{SOMBOR}, \mathrm{AM}, \mathrm{ZZ}$ and DD. 


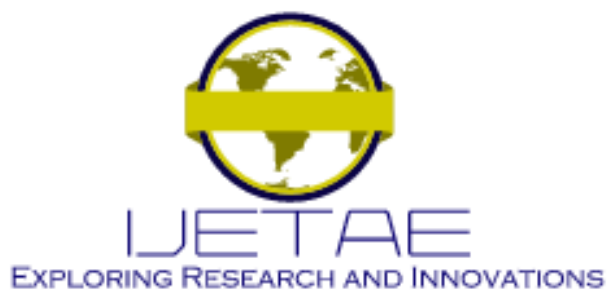

International Journal of Emerging Technology and Advanced Engineering Website: www.ijetae.com (E-ISSN 2250-2459, Scopus Indexed, ISO 9001:2008 Certified Journal, Volume 11, Issue 11, November 2021)

While for LUMO, the performance achievement of linear regression can be ranked as JJ, HH, DD, AM, ZZ and SOMBOR. Multicollinearity might exist for JJ topology indices because $\mathrm{R}^{2}$ and RMSE also showed high deviation between Linear, Ridge, LASSO and Elastic Net Regression. Ridge regulation also showed the improvement of mathematical model for $\mathrm{HH}, \mathrm{ZZ}$ and DD since their $\mathrm{R}^{2}$ increased and RMSE decreased if compared with the linear regression mathematical model. However, for further investigation, it is suggested to investigate the performance of degree-topology indices with other supervised learning algorithms such as support vector machines, artificial neural network, and decision three.

\section{Acknowledgement}

The authors would like to thank Dr James J. P. Stewart from MOPAC Inc. for his permission to use the MOPAC software. Additionally, the authors wish to express gratitude to Universiti Teknologi MARA for financial assistance.

\section{REFERENCES}

[1] Kohse-Höinghaus, K., Combustion in the future: The importance of chemistry. Proceedings of the Combustion Institute, 2021. 38(1): p. $1-56$.

[2] Hemmati-Sarapardeh, A., et al., Applications of artificial intelligence techniques in the petroleum industry. 2020: Gulf Professional Publishing.

[3] Morgan, D. and R. Jacobs, Opportunities and challenges for machine learning in materials science. Annual Review of Materials Research, 2020. 50: p. 71-103.

[4] Aldosari, M.N., et al., Predicting entropy and heat capacity of hydrocarbons using machine learning. Energy and AI, 2021. 4: p. 100054.

[5] Chatterjee, S., F. Liu, and F. Wang, Differentiation of alkyl radicals: A route through chemical graph theory. International Journal of Quantum Chemistry, 2021. 121(7): p. e26567.

[6] Sporns, O., Graph theory methods: applications in brain networks. Dialogues in clinical neuroscience, 2018. 20(2): p. 111.

[7] Pompe, M., et al., Using variable and fixed topological indices for the prediction of reaction rate constants of volatile unsaturated hydrocarbons with $\mathrm{OH}$ radicals. Molecules, 2004. 9(12): p. 11601176.

[8] Wiener, H., Structural Determination of Paraffin Boiling Points. Journal of the American Chemical Society, 1947. 69(1): p. 17-20.

[9] Platt, J.R., Influence of neighbor bonds on additive bond properties in paraffins. The Journal of Chemical Physics, 1947. 15(6): p. 419420.

[10] Dearden, J.C., The use of topological indices in QSAR and QSPR modeling, in Advances in QSAR modeling. 2017, Springer. p. 57-88.
[11] Gao, W., et al., Some reverse degree-based topological indices and polynomials of dendrimers. Mathematics, 2018. 6(10): p. 214.

[12] Rybińska-Fryca, A., A. Mikolajczyk, and T. Puzyn, Structureactivity prediction networks (SAPNets): a step beyond Nano-QSAR for effective implementation of the safe-by-design concept Nanoscale, 2020. 12(40): p. 20669-20676.

[13] Muratov, E.N., et al., QSAR without borders. Chemical Society Reviews, 2020. 49(11): p. 3525-3564.

[14] Mao, J.X., P. Kroll, and K.A. Schug, Vacuum ultraviolet absorbance of alkanes: an experimental and theoretical investigation. Structural Chemistry, 2019. 30(6): p. 2217-2224.

[15] Gutman, I., Degree-based topological indices. Croatica chemica acta, 2013. 86(4): p. 351-361.

[16] Cao, J., et al., Zagreb Connection Indices of Molecular Graphs Based on Operations. Complexity, 2020. 2020: p. 7385682.

[17] Chu, Y.-M., et al., Degree- and irregularity-based molecular descriptors for benzenoid systems. The European Physical Journal Plus, 2021. 136(1): p. 78.

[18] Kumar, K.A., N. Basavarajappa, and Shanmukha, QSPR analysis of Alkanes with certain degree based topological indices. Malaya Journal of Matematik, 2020. 8(2, 2020): p. 314-330.

[19] Barratt, M.D., Prediction of toxicity from chemical structure. Cell biology and toxicology, 2000. 16(1): p. 1-13.

[20] Compton, P., et al. Knowledge based systems that have some idea of their limits. in Tenth Knowledge Acquisition for Knowledge-Based Systems Workshop. 1996.

[21] Yang, H., et al., Corrigendum: In Silico Prediction of Chemical Toxicity for Drug Design Using Machine Learning Methods and Structural Alerts. Frontiers in chemistry, 2018. 6: p. 129.

[22] He, T., et al., The detonation heat prediction of nitrogen-containing compounds based on quantitative structure-activity relationship (QSAR) combined with random forest (RF). Chemometrics and Intelligent Laboratory Systems, 2021. 213: p. 104249.

[23] Ito, R., et al., A novel method for the inverse QSAR/QSPR to monocyclic chemical compounds based on artificial neural networks and integer programming, in Advances in Computer Vision and Computational Biology. 2021, Springer. p. 641-655.

[24] Lu, J., et al., Predicting Rate Constants of Hydroxyl Radical Reactions with Alkanes Using Machine Learning. Journal of Chemical Information and Modeling, 2021.

[25] Nikolić, S., et al., The Zagreb Indices 30 Years After. Croatica Chemica Acta, 2003. 76: p. 113-124.

[26] Furtula, B., A. Graovac, and D. Vukičević, Augmented Zagreb index. Journal of Mathematical Chemistry, 2010. 48(2): p. 370-380.

[27] Cruz, R., I. Gutman, and J. Rada, Sombor index of chemical graphs. Applied Mathematics and Computation, 2021. 399: p. 126018.

[28] Boguñá, M., et al., Network geometry. Nature Reviews Physics, 2021. 3(2): p. 114-135.

[29] Dalfó, C., M.A. Fiol, and E. Garriga, Moments in graphs. Discrete Applied Mathematics, 2013. 161(6): p. 768-777.

[30] Zhou, B., X. Cai, and N. Trinajstić, On Harary index. Journal of Mathematical Chemistry, 2008. 44(2): p. 611-618.

[31] Balaban, A.T., Highly discriminating distance-based topological index. Chemical Physics Letters, 1982. 89(5): p. 399-404. 


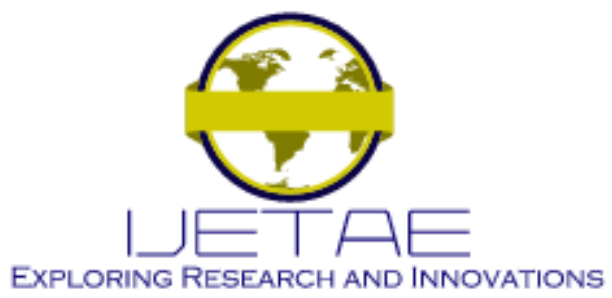

International Journal of Emerging Technology and Advanced Engineering

Website: www.ijetae.com (E-ISSN 2250-2459, Scopus Indexed, ISO 9001:2008 Certified Journal, Volume 11, Issue 11, November 2021)

[32] Alias, A.N., et al., Biological Activity Relationship of Cyclic and Noncyclic Alkanes Using Quantum Molecular Descriptors. Open Journal of Applied Sciences, 2021. 11(8): p. 966-984.

[33] Altelbany, S., Evaluation of Ridge, Elastic Net and Lasso Regression Methods in Precedence of Multicollinearity Problem: A Simulation Study. Journal of Applied Economics and Business Studies, 2021. 5(1): p. 131-142.
[34] Li, Z., et al., Machine-Learning Energy Gaps of Porphyrins with Molecular Graph Representations. The Journal of Physical Chemistry A, 2018. 122(18): p. 4571-4578.

[35] Pereira, F., et al., Machine Learning Methods to Predict Density Functional Theory B3LYP Energies of HOMO and LUMO Orbitals. Journal of Chemical Information and Modeling, 2017. 57(1): p. $11-21$ 